\title{
Aquisição da correferência pronominal catafórica no português europeu por aprendentes chineses
}

\author{
Yi Zheng \\ Faculdade de Letras da Universidade de Lisboa \\ Centro de Linguística da Universidade de Lisboa
}

\begin{abstract}
:
This paper aims to investigate how Chinese learners of European Portuguese as second language acquire backward anaphora in this language, analyzing the interpretation of overt pronoun in left-dislocated temporal adverbial adjunct. Two experiments were administered to test if the syntactic position and the proximity of antecedent are main factors to determine the interpretation by the native speakers of Portuguese and the Chinese learners, as well as if the learners are influenced by their first language. The first test illustrates that in Chinese the native speakers may fluctuate between three possible interpretations in backward anaphora structures, namely the matrix subject, matrix object and the antecedent in context. The second test demonstrates that the native speakers of European Portuguese also fluctuate between the three interpretations, while the Chinese learners do not tend to accept an antecedent in the context. The test also shows that the $\mathrm{C} 1$ level learners are more likely to accept the matrix subject as the antecedent of the embedded overt pronoun than the B2 level learners.
\end{abstract}

Keywords: backward anaphora, European Portuguese, Chinese, second language acquisition.

Palavras-chave: catáfora, português europeu, chinês, aquisição da língua segunda.

\section{Introdução}

Nas línguas humanas é usual utilizar expressões de referência dependente (tais como pronome nulos ou plenos) para retomar um constituinte já referido, establecendo assim relações anafóricas. Frequentemente, as expressões de referência dependente aparecem depois do seu antecedente, constituindo instâncias de anáfora (neste trabalho referida como condição de anáfora). No entanto, em alguns casos, as expressões de referência dependente também podem preceder o seu antecedente, sendo assim designadas como casos de catáfora (neste estudo mencionada como condição de catáfora).

Muitos dos trabalhos sobre a interpretação e processamento da correferência pronominal (e.g Costa et al. 1998; Carminati 2002; Morgado 2011; Luegi 2012; Fukumura \& van Gompel 2015) e a sua aquisição em língua segunda (L2) (Rotheman 2008; Madeira et al. 2012) concentram-se na condição de anáfora. Não é claro se as propriedades relacionadas com a anáfora (a preferência pelo antecedente sujeito para pronome nulo e a preferência pelo 
antecedente não-sujeito para pronome pleno) também funcionam em catáfora, nem se os aprendentes de L2 têm as mesmas interpretações na catáfora e na anáfora.

Este trabalho visa analisar a resolução catafórica pronominal no Português Europeu (PE) e a sua aquisição como L2 por aprendentes chineses. Os trabalhos sobre o italiano (Sorace \& Filiaci 2006; Serratrice 2007) mostram que os falantes nativos desta língua exibem uma preferência semelhante em catáfora e na anáfora, que está intimamente relacionada com a posição sintática dos antecedentes, isto é, preferem o sujeito matriz como antecedente do pronome catafórico nulo e preferem um antecedente exofórico para o pronome pleno. Este trabalho propõe-se testar se o PE, uma língua românica de sujeito nulo parecida com o italiano, também tem uma interpretação semelhante. Procurará mostrar que o chinês, uma língua de sujeito nulo discursivo, pode ter duas interpretações diferentes para a condição catafórica, dependendo da estrutura sintática. Este estudo vai ainda testar como os aprendentes chinese do PE-L2 interpretam a catáfora do PE e se estão influenciados pelas propriedades da sua língua materna.

Para o presente estudo foram elaborados testes preliminares para testar a interpretação das estruturas de frase adjunta adverbial temporal deslocada à esquerda no PE e a sua aquisição por aprendentes chineses do PE-L2. A primeira experiência experimental foi um teste off-line de juízo de preferência feita no chinês, para esclarecer a interpretação catafórica na língua materna dos aprendentes. A segunda experiência experimental foi também um teste off-line de juízo de preferência, feita no PE, para testar a interpretação dos falantes nativos desta língua, bem como a dos aprendentes chineses do PE-L2.

O presente trabalho tem a seguinte estrutura: A secção 2 ilustra os trabalhos anteriores sobre a interpretação e aquisição da resolução anafórica e catafórica. A secção 3 apresenta os objetivos do trabalho e os testes experimentais. A secção 4 analisa os dados obtidos nos testes experimentais. Por fim, na secção 5 apresentam-se as conclusões e uma previsão do trabalho futuro.

\section{Os trabalhos anteriores}

\subsection{Anáfora}

Nas línguas românicas de sujeito nulo, os pronomes nulos e plenos podem mostrar propriedades complementares, considerando as suas potencialidades referenciais nas estruturas anafóricas. Tal como Costa et al. $(1998 ; 1999)$ mostram, no PE o pronome nulo é 
preferencialmente interpretado como retomando o sujeito, enquanto o pronome pleno é preferencialmente interpretado como retomando um não-sujeito. Propostas semelhantes foram apresentadas para o PE por Brito (1991), Canceiro (2014; 2016), etc.

(1) O João 1 viu o Pedro 2 quando $[-]_{1, ? 2}$ entrou no cinema.

(2) O João1 viu o Pedro2 quando ele?1,2 entrou no cinema. (Adaptadas de Costa et al. 1998)

Por outro lado, o chinês, apesar de ser uma língua de sujeito nulo, apresenta algumas propriedades diferentes, quando comparado com o PE. O pronome nulo no chinês pode ser tanto um pro (que não tem a ver com a flexão verbal) como uma variável ligada pelo tópico (Huang 1984), e não existe necessariamente uma diferença entre o pronome nulo e pleno em termos da sua referência, uma vez que tanto um pro como um pronome pleno podem referir-se ao sujeito matriz ou ao objeto matriz, segundo trabalhos como o de Huang (1982).

$$
\begin{aligned}
& \text { Zhangsan }_{1} \text { gaosu Lisi } 2[-]_{1,2} / \operatorname{ta}_{1,2} \text { de jiang le. } \\
& \text { Zhangsan dizer Lisi ele ganhar prémio Pst. } \\
& \text { 'O Zhangsan disse ao Lisi que (ele) ganhou o prémio.' }
\end{aligned}
$$

Em termos de processamento, considerando a carga de memória, Ariel (1990; 2001) propõe a Teoria da Acessibilidade, que defende que existe uma escala de marcação de acessibilidade entre as expressões anafóricas. De um modo geral, as expressões que apresentam mais informação referencial (por exemplo, DP pleno ou pronomes fortes) devem retomar um antecedente menos acessível, enquanto as expressões que têm menos informação referencial (por exemplo, pronomes nulos) devem retomar um antecedente mais acessível. O nível de acessibilidade de um constituinte pode ser decidido por vários fatores, entre quais a saliência. De um modo geral, um consitituinte mais saliente ganha mais acessibilidade, enquanto um constituinte menos saliente ganha menos acessibilidade.

Inspirada na Teoria de Acessibilidade, Carminati (2002) propõe a Hipótese da Posição de Antecedente (HPA), que analisa a correferência nominal e pronominal considerando a função e posição sintática do antecedente das expressões anafóricas. A complementaridade entre o pronome nulo e pleno mostrada em (1) e (2) foi testado na HPA, que defende que na 
resolução pronominal anafórica intrafrásica, um sujeito nulo procura um antecedente na posição de sujeito (SpecIP), que é mais saliente, enquanto um sujeito pleno procura um antecedente noutras posições. Esta hipótese implica que a resolução anafórica é decidida pela posição sintática do antecedente e é este fator, na proposta de Carminati (2002), que define a saliência do antecedente. Propostas semelhantes foram apresentadas para o PE por trabalhos como Costa et al. (1998), Morgado (2011).

Em termos de aquisição de L2, Sorace \& Filiaci (2006) propõem a Hipótese de Interface, defendendo que na aquisição de L2, enquanto os aspetos puramente sintáticos podem ser adquiridos, os aspetos de interface, como, por exemplo, os que envolvem a interface entre a sintaxe e os aspetos pragmático- discursivos, são difíceis de adquirir, mesmo para os falantes quase-nativos. White (2011) defende que a Hipótese de Interface deve ser alargada também aos falantes que se encontram no processo de aquisição de L2.

Um dos exemplos mais estudados da interface entre a sintaxe e os aspetos pragmáticodiscursivos é o da aquisição de sujeito nulo e pleno das línguas de sujeito nulo consistente. Vários trabalhos, incluindo os de Sorace \& Filiaci (2006), Rothman (2008), Madeira et al. (2012) e Zheng (2013) mostram que, para as línguas românicas de sujeito nulo, os aprendentes de L2 têm algumas dificuldades em adquirir o uso discursivo dos pronomes nulos e plenos.

Por exemplo, numa frase como (4), os falantes nativos do PE preferem a correferência entre o sujeito encaixado nulo e o sujeito matriz, e a leitura disjunta entre o sujeito pleno e o sujeito matriz, segundo a HPA.

(4) A Inês vive com a Ana desde que pro/ela se divorciou. (adaptada de Madeira et al. 2012)

(Falantes nativos: pro $=$ Inês, ela $=$ Ana; aprendentes chineses do PE-L2: pro $=$ Inês, ela $=$ Inês ou Ana)

No entanto, a interpretação dos aprendentes de L2 (incluindo aprendentes do chinês) é diferente da dos falantes nativos. Para a condição de sujeito nulo, eles também aceitam a correferência entre o sujeito nulo e o sujeito matriz (embora Zheng 2013 mostre que os aprendentes chineses também podem aceitar a correferência entre o sujeito nulo e o objeto), mas, para a condição de sujeito pleno, apesar de aceitarem a correferência entre o sujeito pronominal encaixado e o objeto, eles ainda aceitam a correferência entre o sujeito pronominal 
e o sujeito matriz, incluindo os aprendentes cuja língua materna possui sujeito nulo consistente. Segundo a Hipótese de Interface, como esta propriedade das línguas de sujeito nulo consistente se encontra na interface entre a sintaxe e o discurso, ela será difícil de ser adquirida pelos aprendentes de L2, que, por consequência, vão mostrar interpretações indeterminadas, i.e., às vezes aceitam a correferência entre o sujeito matriz e o pronome pleno, e às vezes aceitam a correferência entre o objeto matriz e o pronome pleno.

\subsection{Catáfora}

\subsubsection{A estrutura sintática da catáfora}

Agora vejamos o caso da catáfora. Primeiro analiso a estrutura sintática das construções catafóricas do PE. O presente trabalho vai analisar os pronomes que ocorrem em posição de sujeito frásico de frases adverbiais temporais ocorrendo na periferia esquerda da frase matriz. No PE, as frases adverbiais temporais são consideradas como CPs em que o conetor temporal, como quando, ocupa a posição de núcleo do CP, enquanto o resto é uma oração finita. Note-se, porém, que Móia (2001) considera o conetor temporal quando do PE como um pronome relativo, (que encabeça uma relativa livre), equivalente a 'na altura em que'.

Segundo trabalhos como o de Valmala (2009), as adjuntas adverbiais ocorrem na periferia esquerda em frases e podem ter a seguinte estrutura, (5), em que a oração subordinada está inserida diretamente na posição de TopP, que se encontra na periferia esquerda da frase no sistema CP (Rizzi 1997) da oração matriz.

(5) $\left[\mathrm{CP}_{1}\left[\mathrm{TopP} \mathrm{P}_{1}\left[\mathrm{CP}_{2}[\mathrm{C}\right.\right.\right.$ Quando $]\left[\mathrm{TP}_{2}\right.$ ele chegou a casa $\left.\left.]\right]\right] \ldots\left[\mathrm{TP}_{1}\right.$ o João chamou o Rui $\left.]\right]$.

Barss (1986), Duarte (1987) e Lasnik \& Saito (1991) propõem que a adjunta adverbial integrada deve ser tratada como uma adjunção à esquerda a TP (como um caso de scrambling).

\footnotetext{
${ }^{1}$ Este trabalho não vai discutir se é adequado adotar a proposta de Móia para as adjuntas adverbiais temporais do PE, visto que em nenhuma estrutura catafórica apresentada em baixo (cf. (5) e (6)) o sujeito da oração subordinada pode c-comandar o sujeito matriz, independentemente de a adverbial ter por núcleo uma conjunção subordinativa ou ser analisada como uma relativa livre. No entanto, para as estruturas do chinês, este trabalho vai apresentar o confronto entre a estrutura com preposição e a estrutura sem preposição, mostrando que é mais adequado analisar a estrutura com preposição como uma relativa, veja-se (9) e (11).
} 
De acordo com esta proposta, a adjunta adverbial é movida para a esquerda e fica em adjunção a TP.

(6) $\left[\mathrm{CP}_{1}\left[\mathrm{TP}_{1}\left[\mathrm{CP}_{2}[\mathrm{C} \text { Quando }]\left[\mathrm{TP}_{2} \text { ele chegou a casa }\right]\right]_{1}\left[\mathrm{TP}_{1}\right.\right.\right.$ o João chamou o Rui $\left.\left.\left.[-]_{1}\right]\right]\right]$.

Tanto em (5) e (6), o sujeito da oração subordinada é dominado pelo nó $\mathrm{TP}_{2}$ e não ccomanda o sujeito matriz. Desta forma, a correferência entre o sujeito subordinado (que é o pronome encaixado) e o sujeito matriz não viola o princípio $C$ de ligação, uma vez que o primeiro não c-comanda o segundo.

Baseando-se na estrutura (5), e através de um teste off-line, Canceiro (2014; 2016) admite que no PE, um pronome nulo encaixado se refere ao sujeito matriz, enquanto um pronome pleno pode referir-se tanto ao sujeito matriz como a uma outra entidade exofórica.

(7) a. Uma vez que [- $]_{1}$ sai tarde, o filho da Maria 1 chega sempre atrasado.

b. Uma vez que ele 1,2 sai tarde, o filho da Maria 1 chega sempre atrasado.

(adaptadas de Canceiro 2014)

No entanto, o que se mostra em Canceiro $(2014 ; 2016)$ sobre a interpretação do pronome pleno é contrário aos dados obtidos para o italiano. Segundo Sorace \& Filiaci (2006) e Serratrice (2007), em italiano, os falantes nativos preferem interpretar o pronome pleno catafórico como referir-se a um constituinte exofórico, que não é referido no enunciado, em vez de aos argumentos da oração matriz. Quanto ao pronome nulo catafórico, o italiano também prefere o sujeito matriz como seu antecedente.

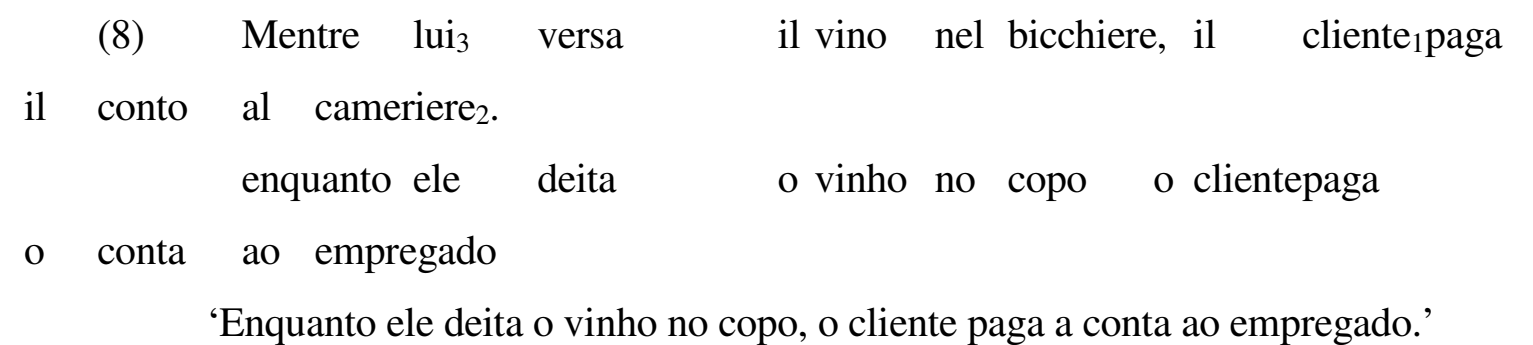

(Serratrice 2007) 
O chinês apresenta propriedades diferentes relativamente ao PE, na interpretação dos pronomes plenos. Zhao (2014) propõe que o chinês não permite a correferência entre o pronome pleno catafórico e o sujeito matriz, o que é consistente com a interpretação preferida do italiano. No entanto, esta coincidência de interpretação destas duas línguas tem naturezas distintas. Para o italiano, a leitura desfavorecida da correferência entre o pronome pleno catafórico e o sujeito matriz é apenas uma questão pragmática, uma vez que a estrutura sintática não impede esta interpretação. Pelo contrário, para o chinês, a impossibilidade da correferência pode ter uma causa sintática. Zhao (2014) defende que no chinês pode existir uma relação de c-comando entre o pronome encaixado e o sujeito matriz. Em (9), uma oração adverbial temporal deslocada à esquerda é analisada como um $\mathrm{CP}$ de núcleo final, em que a palavra temporal de shihou ‘quando' fica na posição de C da oração subordinada.

(9) $\left[\mathrm{CP}\left[\mathrm{TP} \mathrm{Ta}_{1}\right.\right.$ chiwanfan] [C de shihou]], Zhangsan 2 dai zhe yi ding maozi. he eat dinner DE when Zhangsan wearPRG oneCL hat

'When he was having dinner, Zhangsan was wearing a hat.'

'Enquanto ele jantava, o Zhangsan usava um chapéu.'

(Zhao 2014)

A oração subordinada adverbial $(\mathrm{CP})$ c-comanda o sujeito matriz, enquanto o pronome encaixado $t a$ 'ele' fica numa estrutura mais baixa, mas segundo o c-comando cíclico de Huang (1982), o ta 'ele' pode c-comandar ciclicamente o sujeito matriz. O conceito de c-comando cíclico é definido da forma seguinte:

(10) A cyclic c-commands B if and only if:

a. A c-commands B, or

b. If $\mathrm{C}$ is the minimal cyclic node (NP or S') that dominates $\mathrm{A}$ but is not immediately dominated by another cyclic node, then $\mathrm{C}$ c-commands $\mathrm{B}$.

(Huang 1982: 394)

Zhao (2014) identifica S' com CP. Desta forma, em (9), como o pronome encaixado ta 'ele' está contido no CP da subordinada, considerado como um nó cíclico (em inglês cyclic node), que c-comanda o sujeito matriz, $t a$ 'ele' também pode c-comandar ciclicamente o sujeito 
matriz. Com efeito, o chinês não permite a correferência entre o pronome pleno encaixado e o sujeito matriz numa estrutura como (9), porque com o c-comando cíclico, tal correferência vai violar o princípio C de ligação. No entanto, se o sujeito encaixado for nulo, pode existir correferência entre o sujeito nulo encaixado e o sujeito matriz, porque, neste caso, o sujeito nulo pode ser um tópico nulo (inicialmente proposta por Zhao 2012).

No entanto, tal como se mostra na glosa, Zhao (2014) considera que o núcleo da oração subordinada de (9) de shihou é um conetor temporal equivalente a 'when' do inglês ('quando' no caso do PE). No entanto, a palavra shihou no chinês tem o significado de 'altura', enquanto de é o morfema que introduz oração relativa, o que nos leva a reconsiderar a estrutura da oração subordinada de (9) como uma relativa, no sentido de Móia (2001).

De facto, em (9), se adicionar uma preposição zai 'em' antes do pronome encaixado ta 'ele', a frase também está correta, como se mostra em (11). Defendo, pois, que a adjunta adverbial temporal é de facto um PP que contém uma oração relativa. A expressão de shihou, que em (9) é traduzida como ‘when/quando’ e considerada como núcleo da oração subordinada, não é, de facto, um conetor temporal que introduz uma adjunta adverbial temporal, mas é, sim, o núcleo de uma oração relativa, e deve ser traduzida como 'altura/momento'. A preposição zai ‘em' em (11) é o núcleo do constituinte adjunto com valor adverbial que tem a natureza de um PP, e a oração deve ser traduzida como 'na altura em que ele jantava'.

(11)

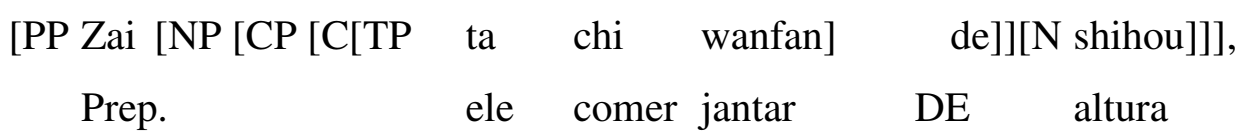

$\begin{array}{lll}\text { Zhangsandai zhe yi } & \text { ding maozi. } \\ \text { Zhangsanvestir PRG } & \text { um CL chapéu }\end{array}$

'Na altura em que ele jantava, o Zhangsan usava um chapéu.'

Em (11), o núcleo da oração subordinada é a preposição zai 'em', que c-comanda o sujeito matriz Zhangsan. Neste caso, o pronome encaixado ta 'ele', que continua a ser dominado pelo núcleo da oração relativa shihou 'altura', não pode c-comandar ciclicamente o sujeito matriz, uma vez que a preposição zai 'em' domina o núcleo da relativa shihou 'altura', que implica que o pronome $t a$ 'ele' não está dominado imediatamente pela preposição zai 'em', e, por consequência, não pode c-comandar ciclicamente o sujeito matriz (por violar 10b). Com 
efeito, em termos sintáticos, o pronome encaixado em (11) continua a poder referir-se ao sujeito matriz, e a sua interpretação volta a ser uma questão pragmática (veja-se a experiência 1 em baixo).

Por isso, considerando a adjunta adverbial temporal, o chinês apresenta duas estruturas sintáticas distintas, que podem implicar interpretações diferentes.

\subsubsection{O processamento da catáfora}

A secção anterior mostra que, em termos sintáticos, o pronome encaixado nas estruturas de catáfora do PE pode referir-se tanto ao sujeito matriz como a um outro constituinte. Por isso, a sua interpretação continua a ser uma questão pragmática, tal como acontece na anáfora. Isto implica que os fatores de processamento também devem ter um papel importante relativamente à resolução catafórica. Desta forma, é também natural considerar que os fatores de processamento que determinam a resolução pronominal anafórica também determinam a resolução catafórica.

De facto, a HPA nas condições de anáfora implica que o fator decisivo para a resolução anafórica é a posição sintática. Se este fator continuar a determinar a resolução pronominal catafórica, os pronomes catafóricos devem ser interpretados preferencialmente como um constituinte com certa posição sintática (e. g. O pronome nulo prefere um antecedente na posição de sujeito). Os dados de Sorace \& Filiaci (2006) e de Serratrice (2007) parecem mostrar que a resolução catafórica do italiano respeita este fator, mas para o caso do PE, Canceiro (2014; 2016) mostra que apenas o pronome nulo apresenta preferência pelo sujeito matriz, enquanto o pronome pleno não apresenta uma preferência clara por um constituinte com uma posição sintática específica. Note-se que os exemplos testados em Canceiro $(2014 ; 2016)$ não incluem o objeto matriz como um antecedente potencial do pronome encaixado (veja-se 7). Se incluissem também o objeto matriz, poderiam apresentar resultados diferentes.

No entanto, o processamento de catáfora pode ser mais complicado do que o de anáfora, uma vez que a expressão catafórica precede os seus antecedentes potenciais. Como o processamento é sempre incremental da esquerda para a direita, esta ordem linear entre a expressão catafórica e os seus antecedentes potenciais pode aumentar o custo de processamento.

Kazanina et al. (2007) propõem um mecanismo de active search, que defende que a resolução catafórica em adjunta adverbial é muito semelhante ao caso de estratégia de fillergap, de movimento-Wh, desenvolvida por trabalhos como Frazier et al. (1983). Por exemplo, 
para uma língua com movimento-Wh, quando o leitor encontra um constituinte-Wh, vai ativar um mecanismo para procurar um gap, que é a posição inicial do constituinte-Wh. Neste processo, como a memória de trabalho não é ilimitada, o leitor vai preferir encontrar o gap o mais rápidamente possível e considerar o primeiro constituinte vazio adequado que encontra como a posição inicial do constituinte-Wh. Assim, podemos inferir que em (12), a leitura 1 é preferencial à leitura 2, ou seja, o leitor deve preferir interpretar (12) como 'quando é que o João disse aquele frase', em vez de a interpretar como 'quando é que o Rui comprou o carro, segundo o que o João tinha dito', uma vez que o gap de 1 se encontra mais perto do constituinteWh ‘quando', pois este vai ter escopo sobre a oração matriz.

(12) Quando é que o João disse $[-]_{1}$ que o Rui comprou um carro $[-]_{2}$ ?

Kazanina et al. (2007) acham que a resolução catafórica é parecida com o caso (12). Na adjunta adverbial deslocada à esquerda, o leitor vai primeiro encontrar um pronome, nulo ou pleno, um constituinte cuja referência é dependente. Desta forma, vai ativar o mesmo mecanismo que em (12) para procurar o antecedente deste pronome. Mais uma vez, devido às limitações da memória, o leitor deve preferir o primeiro elemento nominal que encontra como o antecedente do pronome catafórico, veja-se (13). Um teste de leitura auto-monitorizada corroborou esta afirmação.

(13) Because last semester while she ${ }_{1}$ was taking classes full-time Kathryn ${ }_{1}$ was working two jobs to pay the bills, Erica 2 never got to see her. (adaptada de Kazanina et al. 2007)

Desta maneira, segundo esta hipótese, o pronome catafórico encaixado, quer nulo quer pleno, deve preferir o sujeito matriz, que é o primeiro constituinte nominal encontrado, como seu antecedente. Esta proposta implica que a proximidade linear entre o pronome e o seu antecedente é o fator decisivo para a resolução catafórica, e não deve existir diferença entre o pronome nulo e o pronome pleno.

Segundo os dados apresentados por Sorace \& Filiaci (2006) e Serratrice (2007), esta hipótese não funciona com os falantes nativos do italiano, uma vez que eles preferem que o antecedente se encontre no contexto anterior. No entanto, para os aprendentes do italiano-L2 
(Sorace \& Filiaci 2006) ou bilingues do italiano e inglês (Serratrice 2007), tanto o pronome nulo como o pronome pleno vão procurar o sujeito matriz como seu antecedente, devido ao aumento de custo de processamento em catáfora. Esta interpretação, de facto, corresponde ao mecanismo de active search de Kazanina et al. (2007).

\section{Os objetivos do trabalho}

Este trabalho tem dois objetivos. O primeiro objetivo é testar como é a interpretação dos pronomes encaixados nas estruturas catafóricas do PE pelos falantes nativos, tomando a adjunta adverbial temporal como estrutura de análise. Vai-se testar se a resolução catafórica é determinada através da posição e função sintática do antecedente, ou através da proximidade entre a expressão catafórica e o seu antecedente. No primeiro caso, o pronome nulo deve procurar um antecedente na posição de sujeito, que é mais saliente, enquanto o pronome pleno deve procurar um antecedente noutra posição. Se isto se verificar, tal significa que a resolução catafórica do PE é igual à do italiano, e igual à da anáfora. No segundo caso, se a proximidade for o fator decisivo, tanto o pronome nulo como o pronome pleno devem procurar o sujeito matriz como o seu antecedente, uma vez que este é o mais próximo do pronome catafórico. Nota-se que para o pronome nulo encaixado, tanto a posição sintática como a proximidade predizem a mesma interpretação, enquanto para o pronome pleno, o fator posição sintática prediz o antecedente não sujeito, mas o fator proximidade prediz o antecedente sujeito. Com efeito, em catáfora, o caso de pronome pleno é mais complicado e interessante e vai ser o foco do presente trabalho.

O segundo objetivo do trabalho é testar como os aprendentes chineses do PE-L2 interpretam os pronomes catafóricos na adjunta adverbial temporal deslocada à esquerda do PE. Os aprendentes de L2 vão enfrentar a mesma questão que os falantes nativos do PE, isto é, entre a posição/função sintática e a proximidade, qual é o fator que determina a resolução catafórica? Os trabalhos anteriores sobre a aquisição de anáfora (e. g. Sorace \& Filiaci 2006; Rothman 2008; Madeira et al. 2012) e catáfora (e. g. Sorace \& Filiaci 2006) mostram que os aprendentes de L2 têm dificuldades em adquirir as propriedades relacionadas com a função e posição sintática do antecedente, uma vez que estas envolvem-se interface entre a sintaxe e a pragmática. Os aprendentes tendem a aceitar a correferência entre o pronome pleno encaixado e o sujeito matriz, uma leitura marginal para os falantes nativos. Além disso, em termos de proximidade, Kazanina et al. (2007) consideram que o mecanismo de active search é uma 
estratégia universal, o que significa que é mais fácil para os aprendentes de L2 dominar este mecanismo, especialmente quando eles não dominam bem as propriedades de interface, relacionadas com a posição sintática.

Tudo isto prediz que os aprendentes do PE-L2 vão preferir a correferência entre o pronome catafórico (nulo e pleno) e o sujeito matriz nas estruturas de catáfora. Nota-se que no caso do pronome encaixado nulo, o fator posição sintática e o fator proximidade predizem a mesma interpretação. Por isso, é muito provável que os aprendentes de L2 aceitem esta leitura. O que se envolve mais problemas continua a ser o caso de pronome encaixado pleno, em que os dois fatores fazem predições diferentes. Este trabalho vai focar-se no caso de pronome pleno para os aprendentes de L2.

É natural pensar que os aprendentes chineses vão transferir algumas propriedades da sua língua materna para o PE-L2. Contudo, é preciso notar que as propriedades transferidas podem ser tanto aspetos sintáticos como aspetos pragmáticos.

Como se mostrou na secção anterior, as frases com valor de adjuntas adverbias temporais no chinês podem ter duas estruturas. Na estrutura com omissão de preposição (9), a correferência entre o pronome encaixado e o sujeito matriz é impedida por causa de um fator sintático, o c-comando cíclico, que é específico no chinês. Caso os aprendentes transfiram esta propriedade sintática para o PE-L2, vão rejeitar a correferência entre o sujeito matriz e o pronome pleno catafórico. No entanto, na estrutura sem omissão de preposição (11), o ccomando cíclico já não funciona e a correferência entre o pronome catafórico encaixado e o sujeito matriz não deve ser impedida. Desta forma, a interpretação de (11) volta a ser uma questão pragmática. Este trabalho vai testar primeiro a interpretação do chinês em estruturas como (11), e depois testar se os aprendentes de L2 vão transferir esta interpretação para o seu PE-L2.

\section{Os testes experimentais}

\subsection{Os testes realizados}

Foram realizados dois testes experimentais neste trabalho. A experiência 1 é um teste off-line de juízo de preferência aplicado em chinês, para verificar a interpretação dos pronomes catafóricos na língua materna dos aprendentes de L2. Foram testados itens como em (14). Existe uma frase adjunta adverbial deslocada à esquerda, que contém um pronome realizado. A oração matriz contém um sujeito e um objeto direto. Após ler a frase, os participantes vão responder a 
uma pergunta sobre a interpretação desta frase, escolhendo o antecedente do pronome encaixado entre o sujeito matriz, o objeto matriz e uma entidade exofórica. Aqui, utiliza-se a preposição zai 'em' no início da oração subordinada, como na estrutura apresentada em (11). Desta forma, as três interpretações estão todas disponíveis em termos sintáticos. Assim, as respostas dos informantes dever-se-ão apenas aos seus juízos pragmáticos, sem influência dos princípios sintáticos.

(14) Zai ta zuofan de shihou, Yuehan kanjian le Bi'er. 'Quando ele cozinhava, o John viu o Bill.' Shei zai zuofan? 'Quem é que cozinhava?'
A. Yuehan 'John'
B. Bi'er 'Bill'
C. lingwai yige ren 'uma outra pessoa'

Utilizam-se no teste os nomes ingleses mais conhecidos pela sociedade chinesa. Com efeito, muitos nomes chineses não distinguem por si próprios o seu género, ou seja, alguns nomes chineses podem ser tanto masculinos como femininos. Por isso, utilizam-se alguns nomes ingleses, traduzidos para chinês, que são conhecidos, para garantir a congruência de género entre o pronome, o sujeito matriz e o objeto matriz (o pronome $t a$ 'ele/ela' não distingue o género na forma fonológica no chinês, mas, na forma escrita, sim. Como o teste é aplicado com caracteres chineses, os participantes conseguem distinguir o ta para masculino e o ta para feminino). Este teste serve para testar no chinês se os falantes preferem o sujeito matriz, o objeto matriz ou uma entidade exofórica (não especificada) como antecedente do pronome encaixado.

Foram testados 16 itens de teste nesta experiência, juntamente com 32 distratores. Os participantes são 29 falantes nativos do chinês, com idade entre 25 e 36 anos, média de 27.75 . A habilitação escolar mínima dos informantes é licenciatura.

A experiência 2 é também um teste off-line de juízo de preferência, aplicado em PE, para verificar a interpretação dos pronomes catafóricos tanto dos falantes nativos do PE como dos aprendentes chineses do PE-L2. Utilizam-se estruturas semelhantes às do teste em chinês: existe uma frase adjunta adverbial deslocada à esquerda, que contém um pronome realizado. A oração matriz contém um sujeito e um objeto direto. Após ler a frase, os participantes vão responder a uma pergunta sobre a interpretação desta frase, escolhendo o antecedente do pronome encaixado entre o sujeito matriz, o objeto matriz e uma entidade exofórica. 
(15) Quando ela acabou o trabalho, a Joana abraçou a Ana. Quem é que acabou o trabalho?
A. a Joana
B. a Ana
C. uma outra pessoa

Como existe congruência de género entre o pronome, o sujeito matriz e o objeto matriz, esta frase é ambígua e serve para testar se os participantes preferem o sujeito matriz, o objeto matriz, ou uma entidade exofórica (não especificada) como antecedente do pronome encaixado.

Foram testados também 16 itens de teste nesta experiência, juntamente com 32 distratores. Existem três grupos de participantes: dois grupos de aprendentes chineses e um grupo de falantes nativos do PE. Os aprendentes chineses dividem-se em dois níveis, um grupo avançado de $\mathrm{C} 1$, e um grupo intermédio de B2. O grupo de B2 consiste em 19 participantes, com idades entre 20 e 44 anos, média de 22.89. O grupo de $\mathrm{C} 1$ consiste em 12 participantes, com idade entre 19 a 24 anos, média de 21.58. Todos os participantes frequentam curso de Língua e Cultura Portuguesa na Faculdade de Letras da Universidade de Lisboa (FLUL) e o seu nível do português é decidido através de uma avaliação formativa aplicada pelo Instituto da Cultura e Língua Portuguesa da FLUL antes do curso. O grupo de falantes nativos do PE consiste de 19 participantes, com idade entre 19 e 34 anos, média de 21.84. Os participantes frequentam cursos de licenciatura na FLUL.

\subsection{Os resultados dos testes}

Os resulados da experiência 1 estão apresentados no gráfico de barras 1 em baixo. De um modo geral, verifica-se que todas as três interpretações (antecedente sujeito, antecedente objeto e antecedente exofórico) estão disponíveis nas estruturas catafóricas no chinês, quando a oração subordinada deslocada para esquerda contém uma preposição e se forma como um PP, ao contrário dos exemplos de Zhao (2014), em que a preposição está omitida. Comparando-se as três interpretações, o antecedente na posição de sujeito tem a percentagem de aceitação mais alta (41.4\%), seguido pelo antecedente objecto (33.8\%), e por fim, o antecedente exofórico $(24,8 \%)$. No entanto, nenhuma destas interpretações tem uma percentagem superior a $50 \%$, o que significa que nenhuma delas é preferida de forma predominante pelos falantes nativos do chinês. Também não se verificam diferenças significativas entre as três interpretações. 


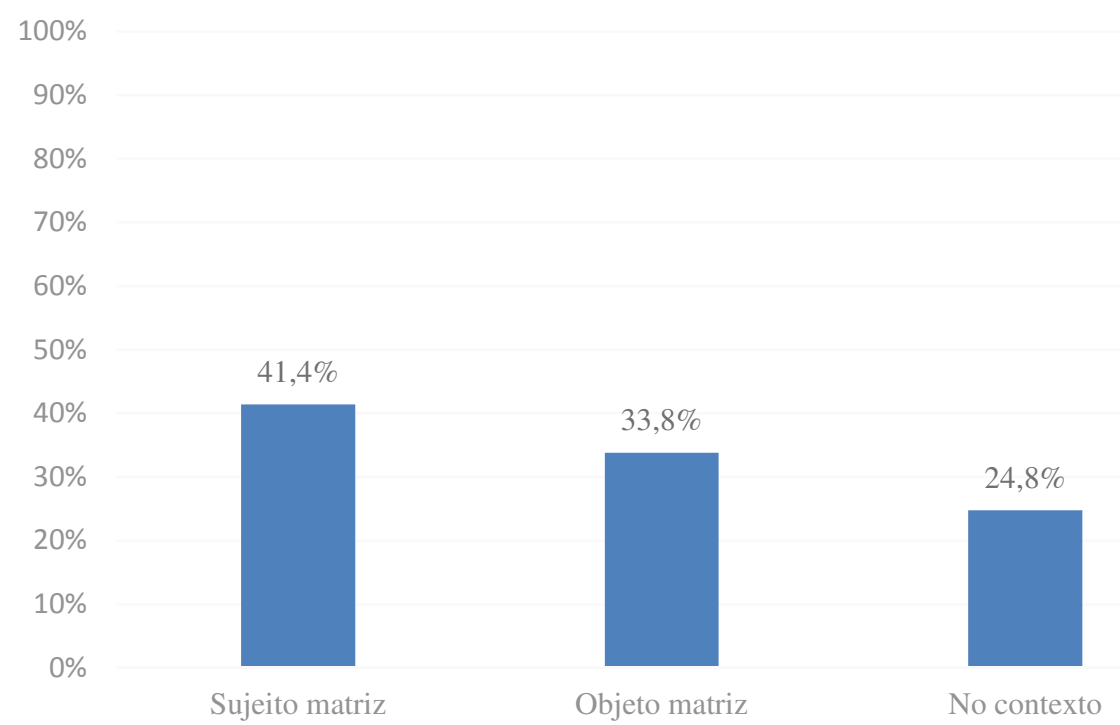

Gráfico de barras 1 - Resultados da experiência 1

Os resultados da experiência 2 estão apresentados no gráfico de barras 2. Primeiro vejamos os dados dos falantes nativos. De um modo geral, a interpretação dos falantes nativos do PE é muito semelhante à dos falantes nativos do chinês. Todas as três interpretações estão disponíveis, embora o antecedente sujeito tenha a percentagem de aceitação mais alta (44.4\%), sendo seguido pelo antecedente objeto $(30.6 \%)$ e pelo antecedente exofórico (25\%). À semelhança do chinês, nenhuma destas interpretações tem uma percentagem superior de $50 \%$, e não se verificam diferenças significativas entre a percentagem de aceitação do antecedente sujeito e do antecedente objeto, $\mathrm{t}_{1}(19)=1.92, \mathrm{p}=0.07, \mathrm{t}_{2}(15)=1.31, \mathrm{p}=0.21$, nem diferenças entre a percentagem de aceitação do antecedente objeto e do antecedente exofórico, $\mathrm{t}_{1}(19)=0.644$, $\mathrm{p}=0.5, \mathrm{t}_{2}(15)=0.598, \mathrm{p}=0.56$, o que significa que os falantes nativos do PE também não mostram uma preferência predominante na interpretação dos pronomes plenos catafóricas, ao contrário dos dados de italiano (Sorace \& Filiaci 2006; Serratrice 2007), em que o antecedente exofórico é predominante.

Quanto aos aprendentes do nível B2, eles flutuam entre o antecedente sujeito (49.7\%) e o antecedente objeto (40.1\%), mas raramente escolham o antecedente exofórico (apenas 10,2\%). Existe diferença significativa entre o antecedente objeto e o antecedente exofórico, por sujeito e por item, $\mathrm{t}_{1}(18)=3.93, \mathrm{p}<0.01, \mathrm{t}_{2}(15)=5,29, \mathrm{p}<0.01$. Não se verifica diferença significativa entre o sujeito matriz e o objeto matriz. Isto mostra que os aprendentes de B2 não 
preferem o antecedente exofórico, mas também não mostram uma preferência clara entre o antecedente sujeito e o antecedente objeto.

Quanto aos aprendentes do nível C1, eles preferem o antecedente sujeito (64.6\%), enquanto as percentagens de aceitação para o antecedente objeto e o antecedente exofórico são relativamente mais baixas $(26.6 \%$ e $8.9 \%$ respetivamente). Existe diferença significativa entre $\mathrm{o}$ antecedente sujeito e o antecedente objeto, por sujeito e por item, $\mathrm{t}_{1}(11)=4.46, \mathrm{p}<0.01$, $\mathrm{t}_{2}(15)=8.26, \mathrm{p}<0.01$. Isto mostra que os aprendentes de $\mathrm{C} 1$ apresentam uma preferência predominante pelo antecedente sujeito, que é parecida com a dos aprendentes do italiano-L2 de Sorace \& Filiaci (2006).

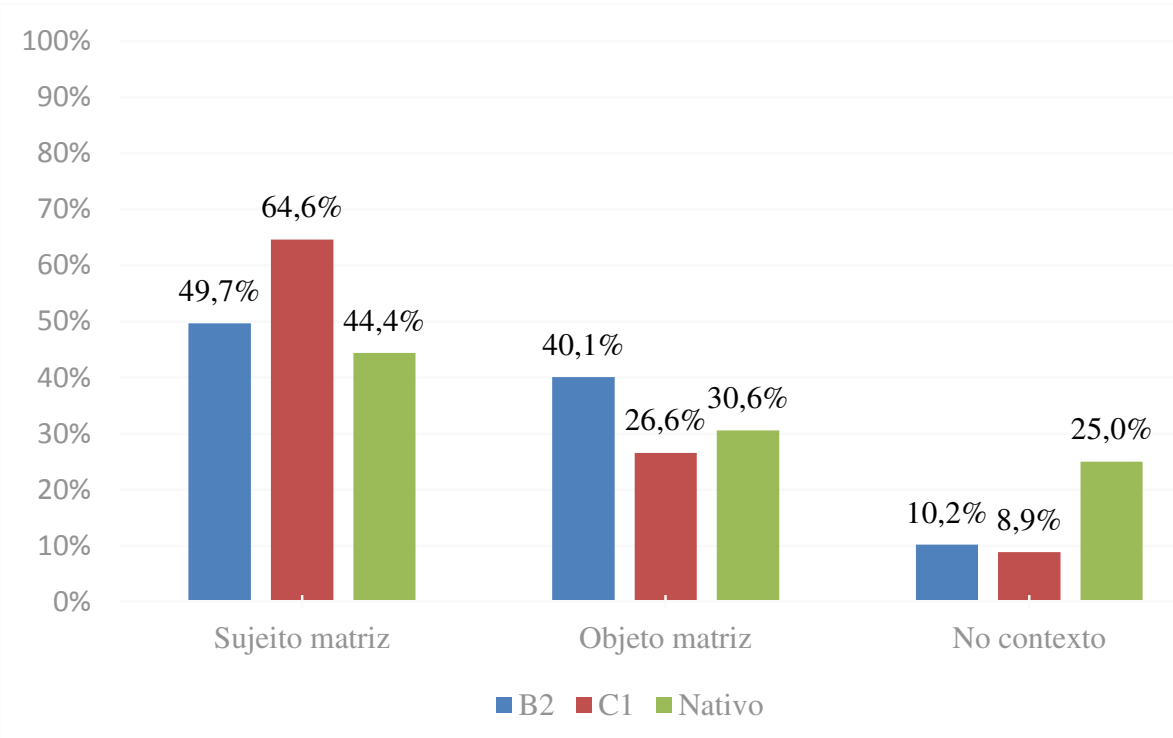

Gráfico de barras 2 - Resultados da experiência 2

Comparando-se os aprendentes de B2 e os falantes nativos, não se verificam diferenças significativas na aceitação dos antecedentes sujeitos e objetos. Existem diferenças significativas no caso do antecedente exofórico, em que os falantes nativos aceitam mais esta interpretação do que os aprendentes de $B 2, F_{1}(1,36)=4.65, p=0.03, F_{2}(1,30)=9.59$, $p<0.01$. Comparando-se os aprendentes de $\mathrm{C} 1$ e os falantes nativos, verifica-se que os aprendentes aceitam mais o antecedente sujeito do que os falantes nativos $\mathrm{F}_{1}(1,29)=7.705, \mathrm{p}=0.01, \mathrm{~F}_{2}(1,30)=7.236$, $\mathrm{p}=0.01$. Verifica-se também que os falantes nativos aceitam mais o antecedente exofórico do que os aprendentes (marginal por sujeito e significativa por item), $F_{1}(1,29)=3.97$, p=0.056, $\mathrm{F}_{2}(1,30)=11.29, \mathrm{p}<0.01$. A diferença principal entre os falantes nativos e os aprendentes é que 
os falantes nativos aceitam o antecedente exofórico, mas os aprendentes raramente têm esta interpretação, $\mathrm{F}_{1}(2,47)=3.417, \mathrm{p}=0.041 ; \mathrm{F}_{2}(2,45)=8.872, \mathrm{p}=0.01$. Comparando-se os dois grupos de aprendentes, os do nível $\mathrm{C} 1$ aceitam mais o antecedente sujeito do que os do nível B2, verificando-se diferenças na percentagem da aceitação, marginal por sujeito e significativa por item, $\mathrm{F}_{1}(1,29)=3.66, \mathrm{p}=0.066, \mathrm{~F}_{2}(1,30)=4.75, \mathrm{p}=0.04$. Ambos grupos não aceitam facilmente o antecedente exofórico.

\subsection{Discussão}

Os dados da experiência 1 mostram que o chinês também aceita a correferência entre o pronome catafórico e o sujeito matriz, desde que a preposição esteja realizada, embora a percentagem não seja muito alta. Esta interpretação é contrária à de Zhao (2014), que só utiliza as frases sem preposições e defende que o chinês não permite esta correferência. No entanto, esta diferença sobre a presença ou ausência de preposição prova a validade do conceito de ccomando cíclico no chinês e constitui um argumento a favor da ideia de analisar a adjunta adverbial temporal no chinês como uma oração relativa. Estas duas questões estão fora do âmbito do presente trabalho, mas os resultados da experiência 1 provam que a impossibilidade da correferência entre o pronome catafórico e o sujeito matriz é apenas restringida pela sintaxe (quando há c-comando cíclico); quando a restrição de sintaxe desaparece, esta correferência continua a ser possível, só que os falantes nativos do chinês também aceitam outros antecedentes para o pronome. Esta flutuação entre o antecedente sujeito e outros antecedentes é uma propriedade relacionada com a interface entre a sintaxe e os aspetos pragmáticodiscursivos.

A experiência 2 mostra que os falantes nativos do PE também flutuam entre o antecedente sujeito e outros antecedentes, e em princípio não há diferença entre a interpretação do chinês e do PE, uma vez que em ambas línguas os falantes aceitam as três interpretações possíveis. O comportamento dos falantes nativos do PE difere do dos italianos, que só aceitam antecedente exofórico. Possivelmente, a flutuação no PE é causada por um efeito combinado entre a posição sintática do antecedente e o mecanismo de active search de Kazanina et al. (2007), que é baseado na proximidade entre a expressão catafórica e o seu antecedente. Por um lado, como o pronome pleno é mais informativo do que o pronome nulo em PE, deve procurar um antecedente não sujeito; por outro lado, o mecanismo de active search exige os falantes nativos procurem um antecedente mais próximo, que é o sujeito matriz. Estes dois fatores 
predizem interpretações diferentes. É possível que a flutuação exibida pelos falantes nativos do PE seja causada pelo efeito combinado deste dois fatores que indicam duas interpretações diferentes.

Quanto aos aprendentes de B2, eles também flutuam entre o antecedente sujeito e antecedente objeto, enquanto a sua percentagem de aceitação para o antecedente é muito semelhante à dos falantes nativos (49.7\% vs. 44.4\%). Além disso, esta percentagem é também próxima da dos falantes nativos do chinês da experiência 1 (41.4\%). Há duas formas possíveis de explicar este fenómeno. Por um lado, tal como acontece com os falantes nativos, também existe um efeito combinado de posição sintática e do mecanismo de active search para os aprendentes, por isso, eles flutuam entre o antecedente sujeito (mais próximo) e o antecedente objeto (não sujeito). Por outro lado, eles podem transferir as propriedades do chinês, visto que quando existe uma preposição na adjunta adverbial temporal, o chinês também exibe uma interpretação indeterminada (como mostra em experiência 1). Se for este o caso, isso significa que os aprendentes não transferem c-comando cíclico, uma propriedade sintática do chinês, para o PE-L2. A única diferença entre os aprendentes de B2 e os falantes nativos de PE é que os aprendentes não aceitam bem o antecedente exofórico, apesar de no chinês esta interpretação ser também possível. Isto pode ser causado pelo facto de o antecedente não estar referido no enunciado, e de os aprendentes não terem recursos suficientes para encontrar este antecedente no contexto, uma vez que esta propriedade já está relacionada com a interface entre a sintaxe e o discurso. Um resultado semelhante foi testado por Zhao (2012), que mostra que os aprendentes ingleses do chinês-L2 têm dificuldades em encontrar um antecedente não referido no enunciado para os pronomes anafóricos do chinês.

Os aprendentes de C1 mostram uma interpretação distinta da dos de B2, uma vez que preferem o antecedente sujeito (64.6\%). Isto pode implicar que os aprendentes de $\mathrm{C} 1$ respeitam o mecanismo de active search de Kazanina et al. (2007), que defendem que o primeiro constituinte da oração matriz, que é o mais próximo, deve ser o antecedente do pronome catafórico. Comparando o comportamento do grupo B2 e C1, verifica-se que são os aprendentes de $\mathrm{B} 2$, mas não os de $\mathrm{C} 1$, que exibem uma interpretação mais parecida com a dos falantes nativos do PE. É óbvio que os aprendentes de C1 não transferem o c-comando cíclico do chinês para a sua L2, nem a interpretação testada na experiência 1. Por isso, é natural questionarmonos porque é que os aprendentes mais avançados $(\mathrm{C} 1)$ não exibem o efeito combinado da 
posição sintática e do mecanismo de active search, e porque é que eles não transferem as propriedades do chinês.

Uma explicação pode ser a seguinte: os aprendentes de B2 ainda não dominam bem a gramática de L2 e estão dependentes da sua língua materna. Quanto à interpretação dos pronomes catafóricos, as propriedades do chinês influenciam a L2 dos aprendentes de B2, por isso eles também exibem flutuação entre o sujeito matriz e outros antecedentes. Quanto aos aprendentes de C1, eles já dominam bem a sua própria L2, só que esta L2 tem alguns aspetos distintos da língua alvo, que é o PE-L1. Por exemplo, a L2 pode ser influenciada pelo mecanismo de active search, que é considerado como universal por Kazanina et al. (2007), por isso, os aprendentes de $\mathrm{C} 1$ preferem o antecedente sujeito em catáfora. Ao mesmo tempo, os aprendentes de C1 também não transferem as propriedades da língua materna porque já dominam a sua própria L2 e deixam de estar dependentes da sua L1.

No entanto, tanto os aprendentes de B2 como os de C1 não preferem o antecedente exofórico. Isto pode implicar que a L2 dos aprendentes de $\mathrm{C} 1$ também tem defeitos quando precisa de recorrer uma entidade exofórica, ou seja, eles só conseguem estabelecer relações anafóricas e catafóricas através dos constituintes referidos no enunciado, mas falham em encontrar um no contexto.

\section{Conclusão e os trabalhos futuros}

Este trabalho elabora um teste preliminar sobre a interpretação dos pronomes catafóricos no PE, bem como a sua aquisição por parte dos aprendentes chineses. A experiência 2 mostra que o PE exibe uma interpretação distinta da do italiano, no que diz respeito à interpretação do pronome pleno nas adjuntas adverbiais temporais deslocadas à esquerda. Esta interpretação específica pode ser influenciada por um efeito combinado entre a posição/função sintática e a proximidade do antecedente. Os aprendentes chineses, porém, mostram uma interpretação distinta da dos falantes nativos. Em primeiro lugar, os aprendentes do nível B2 e C1 não preferem um antecedente exofórico, implicando uma dificuldade em procurar um antecedente exofórico fora do enunciado que lêem. Segundo, os aprendentes de C1 estão também influenciados pelo mecanismo de active search (baseado na proximidade do antecedente) e aceitam mais facilmente a correferência entre o pronome catafórico pleno e o sujeito matriz, aspeto em que diferem dos falantes nativos e dos aprendentes de B2. 
Tal como expliquei na introdução, este trabalho propõe-se elaborar uma abordagem preliminar desta questão. Os trabalhos futuros devem testar os aspetos analisados neste trabalho da forma detalhada. Primeiro, os testes no presente trabalho só analisam a condição com pronome pleno, mas os trabalhos futuros devem comparar a condição de pronome pleno com a condição de pronome nulo, para perceber melhor o papel do fator posição/função sintática na resolução catafórica. Segundo, os testes no presente trabalho são de forma off-line. Os trabalhos futuros devem aplicar também testes on-line para analisar de forma mais precisa o processamento em tempo real dos falantes nativos e dos aprendentes de L2, e comparar os dados dos testes off-line e on-line.

\section{Referências}

Ariel, M. (1990) Accessing noun-phrase antecedents. London: Routledge.

Ariel, M. (2001) Accessibility theory: an overview. Sanders, T., J. Schilperoord \& W. Spooren (eds.). Text representation: linguistic and psycholinguistic aspects. Amsterdam: John Benjamins.

Barss, A. (1986) Chains and anaphoric dependence: on reconstructions and its implications. PhD dissertation, Massachusetts Institute of Technology.

Brito, A. M. (1991) Ligação, co-referência e o princípio evitar pronome. Encontro de Homenagem a Óscar Lopes. Associação Portuguesa de Linguística, pp. 101-121.

Canceiro, N. (2014) Sujeitos omitidos em frases coordenadas canónicas finitas e subordinadas adverbiais integradas e não integradas. Textos Selecionados, XXIX Encontro Nacional da Associação Portuguesa de Linguística, Porto, Associação Portuguesa de Linguística 2014, pp. 145-159.

Canceiro, N. (2016) Coordenação, Subordinação Adverbial e Relações Referenciais entre Sujeitos. Dissertação de Mestrado, Faculdade de Letras da Universidade de Lisboa.

Carminati, M. N. (2002) The processing of Italian subject pronouns. $\mathrm{PhD}$ dissertation, University of Massachusetts at Amherst, Amherst (Ma): GLSA Publications.

Costa, A., I. Faria \& G. Matos (1998) Ambiguidade referencial na identificação do sujeito em estruturas coordenadas. Mota, M. A. \& R. Marquilhas (orgs.) Actas do XIII Encontro 
Nacional da Associação Portuguesa de Linguística. Lisboa: Associação Nacional de Linguística, pp. 173-188.

Costa, A., I. Faria \& G. Matos (1999) Competitive information sources in referential ambiguity resolution. Pinto, $\mathrm{M}^{\mathrm{a}}$ da Graça, J. Veloso e B. Maia (orgs.) Psycholinguistics on the Threshold of the Year 2000 - Proceedings of 5th International Congress of the International Society of Applied Pshycholinguistics (ISAPL 97). Porto: Faculdade de Letras da Universidade do Porto, pp. 133-138.

Duarte, I. (1987) A Construção de Topicalização na Gramática do Português: Regência, Ligação e Condições sobre Movimento. Dissertação de Doutoramento, Universidade de Lisboa.

Frazier, L., C. Clifton \& J. Randall (1983) Filling gaps: decision principals and structure in sentence comprehension. Cognition, 13, pp. 187-222.

Fukumura, K. \& R.P.G van Gompel (2015) Effects of order of mention and grammatical role on anaphora resolution. Journal of Experimental Psychology: Learning, Memory and Cognition, 41, 2, pp. 501-525.

Huang, C. -T. J. (1982) Logical relations in Chinese and the theory of grammar. $\mathrm{PhD}$ dissertation, MIT.

Huang, C.-T. J. (1984) On the Distribution and Reference of Empty Pronouns. Linguistic Inquiry, 15, pp. 531-574.

Kazanina, N., Lau, E., Lieberman, M., Yoshida, M. \& Phillips, C. (2007) The effect of syntactic constraints on the processing of backwards anaphora. Journal of Memory and Language, v56, 3, pp. 384-409.

Lasnik, H. \& M. Saito. (1991) On the subject of infinitives. In L. Dobrin, L. Nichols, and R. Rodriguez (eds.) Papers from the 27th Regional Meeting of the Chicago Linguistic Society, pp. 324-343.

Luegi, P. (2012) Processamento de sujeitos pronominais em Português: efeito da posição estrutural dos antecedentes. Dissertação de Doutoramento, Universidade de Lisboa,.

Madeira, A., M. F. Xavier \& M. L. Crispim (2012) Uso e interpretação de sujeitos pronominais em português L2. A. Costa, C. Flores \& N. Alexandre (orgs.) Textos Selecionados do XXVII Encontro da Associação Portuguesa de Linguística. Lisboa: Associação Portuguesa de Linguística, pp. 376-397. 
Móia, T. (2001) Aspectos Sintctico-Semânticos das Orações Relativas com quando e como. In Actas do XVI Encontro Nacional da Associação Portuguesa de Linguística (Coimbra, 28-30 de Setembro de 2000), Lisboa: Associação Portuguesa de Linguística, pp. 349-361.

Morgado, S. (2011) Processamento da co-referência pronominal: informação sintáctica e semântica. Tese de Mestrado apresentada à Faculdade de Letras da Universidade de Lisboa.

Rizzi, L. (1997) The fine structure of the left periphery. In Elements of grammar: Handbook in Generative Syntax, Haegeman, L.(ed.) Dordrecht: Kluwer, pp. 281-337.

Rothman, J. (2008) How Pragmatically Odd!: Interface Delays and Pronominal Subject Distribution in the L2 Spanish of English Natives. Studies in Hispanic and Lusophone Linguistics, 1, pp. 317-339.

Serratrice, L. (2007) Cross-linguistic influence in the interpretation of anaphoric and cataphoric pronouns in English-Italian bilingual children. Bilingualism: Language and Cognition 10 (3), 2007, pp. 225-238, Cambridge University Press.

Sorace, A. \& F. Filiaci (2006) Anaphora resolution in near-native speakers of Italian. Second Language Research 22:3, pp. 339-368.

Valmala, V. (2009) On the position of central adverbial clauses, Anuario del Seminario de Filología Vasca “Julio de Urquijo”, XLIII, pp. 951-970.

White, L. (2011) The Interface Hypothesis: How far does it extend? Linguistic Approaches to Bilingualism 1:1, Amsterdam: John Benjamins, pp. 108-110.

Zhao, L. X. (2012) Interpretation of Chinese overt and null embedded arguments by Englishspeaking learners. Second Language Research 2012 28, pp. 169-190.

Zhao, L. X. (2014) Ultimate attainment of anaphora resolution in L2 Chinese. Second Language Research, 30:3, pp. 381-407.

Zheng, Y. (2013) Aquisição do sujeito nulo por parte dos alunos chineses que adquirem português europeu como língua segunda. Dissertação de Mestrado, Faculdade de Letras da Universidade de Lisboa. 